\title{
Acute poisoning with acetamiprid: a case report
}

\author{
Selladurai Pirasath ${ }^{1,4^{*}} \mathbb{0}$, Rajaram Senthuran ${ }^{1}$, Chandrakulasegeran Athirayan ${ }^{1}$, Mathyasekeran Gevakaran ${ }^{1}$, \\ Mahesan Guruparan ${ }^{2}$ and Ariaranee Gnanathasan ${ }^{3}$
}

\begin{abstract}
Background: Acetamiprid is a potent new first-generation neonicotinoid insecticide in agricultural practices. It is well described that it has low toxicity among animals and is lethal if consumed in large amounts. However, toxicity in humans is rarely reported in literature. Here, we describe acetamiprid toxicity complicated with severe lactic acidosis, myocardial ischemia, refractory hypotension, and severe hypokalemia in a middle-aged man who presented with deliberate self-harming with acetamiprid poisoning in Sri Lanka.

Case presentation: We describe a case of acute poisoning with an acetamiprid in a middle-aged Sri Lankan Tamil farmer for suicidal purposes following family conflicts with his wife. He presented with severe nausea, vomiting, and altered level of consciousness. He had electrocardiogram changes, hypoxia, and lactic acidosis. With intensive care management including ventilatory support, inotropic therapy along with intraarterial blood pressure monitoring, correction of acidosis, and administration of electrolytes, he made good clinical recovery. He was discharged without any further complications 6 days after ingestion of acetamiprid.
\end{abstract}

Conclusions: This case illustrates a rare, acute poisoning with acetamiprid in human, as well as its clinical manifestations and successful management with supportive therapy. This will be helpful for clinicians to identify clinical manifestations and to guide management of acute poisoning with acetamiprid in the future.

Keywords: Acetamiprid, Lactic acidosis, Myocardial ischemia, Hypotension, Hypokalemia

\section{Background}

Acetamiprid belongs to a new systemic neonicotinoid insecticide that is effectively used for crop protection and flea control in agricultural works [1]. It has low toxicity in mammals, but ingestion of large amounts can cause severe toxicity. It is described in a case report that a buffalo exhibited severe gastrointestinal symptoms and respiratory distress following accidental ingestion of acetamiprid in India [2]. Furthermore, only two cases of ingestion of acetamiprid poisoning in human have been reported in literature [3, 4]. Here, we describe a third case of acetamiprid toxicity complicated with severe lactic

\footnotetext{
*Correspondence: selladuraipirasath81@gmail.com

${ }^{1}$ District General Hospital, Kilinochchi, Sri Lanka

Full list of author information is available at the end of the article
}

acidosis, myocardial ischemia, refractory hypotension, and severe hypokalemia in a middle-aged man following deliberate self-harming with acetamiprid in Sri Lanka.

\section{Case presentation}

A 58-year-old healthy Tamil farmer was admitted to the emergency unit of a district general hospital in Northern Sri Lanka with history of nausea, vomiting, and altered level of consciousness 1 hour after acetamiprid poisoning. He had ingested $150 \mathrm{~g}$ of acetamiprid dissolved in water. On examination, he was conscious with Glasgow Coma Scale score of 14/15 (GCS 14/15), and both pupils were equally reactive to light and $3 \mathrm{~mm}$ in size. His blood pressure was $112 / 65 \mathrm{mmHg}$, pulse 86 beats per minute, respiratory rate 12 breaths per minute, and core body temperature $36.8^{\circ} \mathrm{C}$. The rest of the systemic examinations original author(s) and the source, provide a link to the Creative Commons licence, and indicate if changes were made. The images or other third party material in this article are included in the article's Creative Commons licence, unless indicated otherwise in a credit line to the material. If material is not included in the article's Creative Commons licence and your intended use is not permitted by statutory regulation or exceeds the permitted use, you will need to obtain permission directly from the copyright holder. To view a copy of this licence, visit http://creativecommons.org/licenses/by/4.0/. The Creative Commons Public Domain Dedication waiver (http://creativeco mmons.org/publicdomain/zero/1.0/) applies to the data made available in this article, unless otherwise stated in a credit line to the data. 


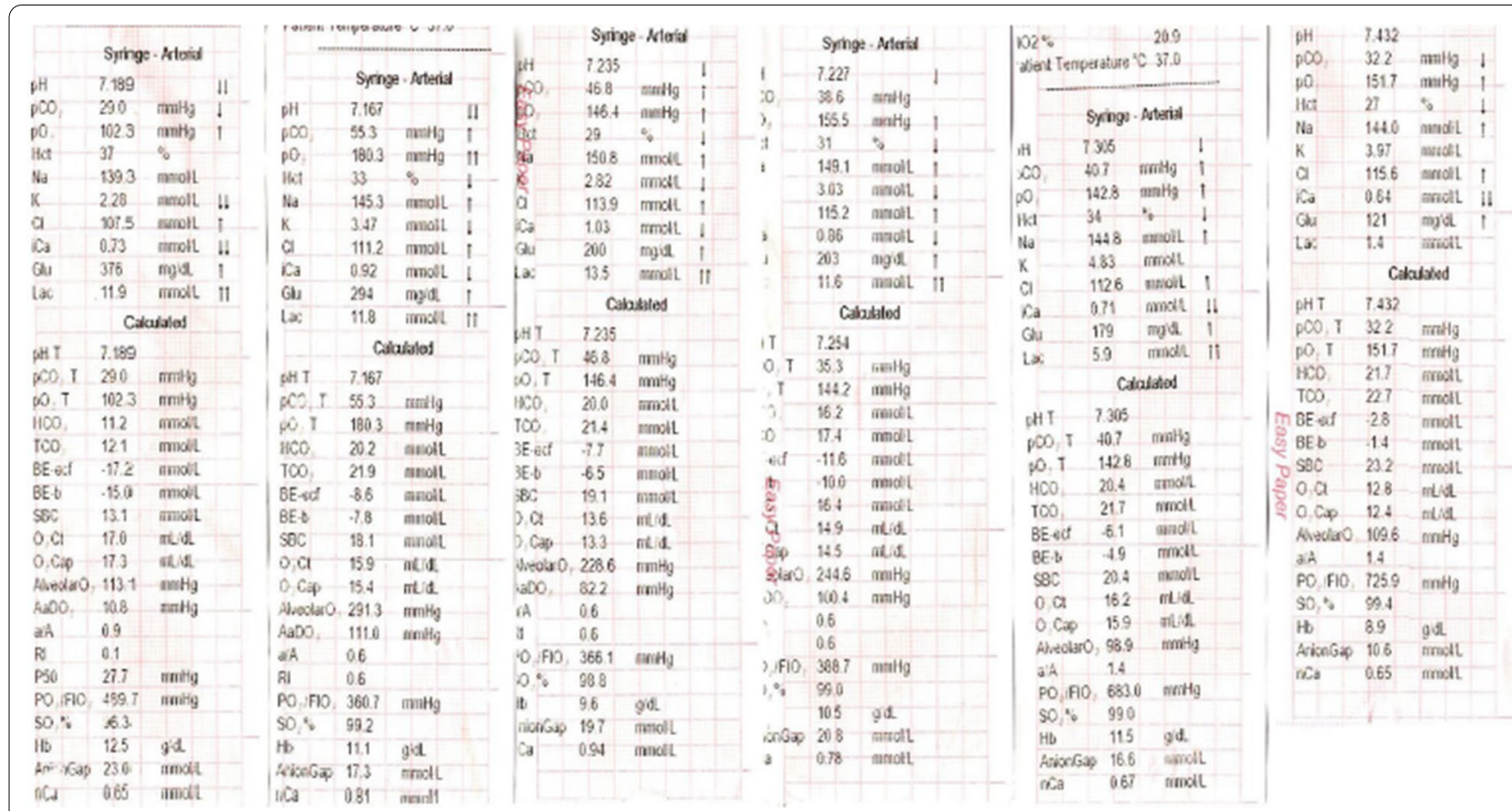

Fig. 1 Serial arterial blood gas reports of patient with acetamiprid poisoning

were unremarkable. Gastric lavage was performed, and a single dose of activated charcoal was administrated. One hour later, he developed reduced level of consciousness with GCS of $8 / 15$. His oxygen saturation dropped to $75 \%$, and blood pressure was $60 / 40 \mathrm{mmHg}$. His arterial blood gas was tested (Fig. 1), showing severe lactic acidosis $\left(\mathrm{pH}\right.$ 7.18, $\mathrm{PaCO}_{2} 29 \mathrm{mmHg}, \mathrm{PaO}_{2} 102.3 \mathrm{mmHg}$, $\mathrm{HCO}_{3}{ }^{-} 11.2 \mathrm{mEq} / \mathrm{L}$, blood lactate $\left.11.9 \mathrm{mmol} / \mathrm{L}\right)$. To correct acidosis, $100 \mathrm{ml}$ of $8.4 \%$ intravenous sodium bicarbonate was given. He was electively intubated. Subsequently, he was given fluid boluses of $30 \mathrm{ml} / \mathrm{kg}$, such as $0.9 \%$ saline $2 \mathrm{~L}, 2 \%$ albumin saline $500 \mathrm{ml}$, and $5 \%$ human albumin $250 \mathrm{ml}$, which was guided according to dynamic parameters of fluid responsiveness such as inferior vena cava distensibility and right ventricular collapse in imaging studies. However, his blood pressure was suboptimal. Therefore, noradrenaline infusion at rate of $0.1 \mu \mathrm{g} / \mathrm{kg} /$ minute was initiated. His 12-lead electrocardiography (ECG) showed ST depression in leads I, II, aVF, and $\mathrm{V}_{3^{-}}$ $\mathrm{V}_{6}$ (Fig. 2). His high-sensitivity troponin I was $571 \mathrm{ng} / \mathrm{L}$. Two-dimensional echocardiography (2D Echo) was done, and it showed mild left ventricular dysfunction with ejection fraction of $45 \%$. Blood results are presented in Table 1 . He had persistent hypotension of $70 / 40 \mathrm{mmHg}$ and severe lactic acidosis despite therapy (Fig. 1).
Subsequently, ultrasound-guided central venous line and intraarterial line were inserted. He was given dobutamine at rate of $10 \mu \mathrm{g} / \mathrm{kg} /$ minute followed by adrenaline infusion of $0.1 \mu \mathrm{g} / \mathrm{kg} /$ minute and vasopressin $1 \mathrm{U} / \mathrm{kg} /$ minute. Despite four inotropes, his blood pressure was suboptimal, and the infusion of noradrenaline, dobutamine, adrenaline, and vasopressin was increased to maximum doses of $0.7 \mu \mathrm{g} / \mathrm{kg} /$ minute, $20 \mu \mathrm{g} / \mathrm{kg} /$ minute, $1 \mu \mathrm{g} / \mathrm{kg} /$ minute, and $3 \mathrm{U} / \mathrm{kg} /$ minute, respectively. His blood pressure was maintained with infusion of four inotropes for 24 hours. Furthermore, $100 \mathrm{ml}, 100 \mathrm{ml}$, and $50 \mathrm{ml}$ of $8.4 \%$ intravenous sodium bicarbonate was repeated to correct acidosis according to calculated deficit and $100 \mathrm{ml} / \mathrm{kg}$ of $0.9 \%$ normal saline as maintenance therapy for the next 36 hours. He had persistent hypokalemia that required intravenous $\mathrm{KCl}$ of $60 \mathrm{mmol}$ over 4 hours, $60 \mathrm{mmol}$ for 3 hours, and $20 \mathrm{mmol}$ for 1 hour. At end of 36 hours, his blood pressure and lactate level were brought to normal level. He was ventilated for 72 hours in the intensive care unit with further supportive therapy. He gradually improved and was extubated on day 3 of his illness. His repeat ECG and 2D Echo showed no abnormalities (Fig. 2). His coronary angiography showed normal coronary epicardial arteries (Fig. 3). He was discharged from hospital on day 6 of hospital admission. 


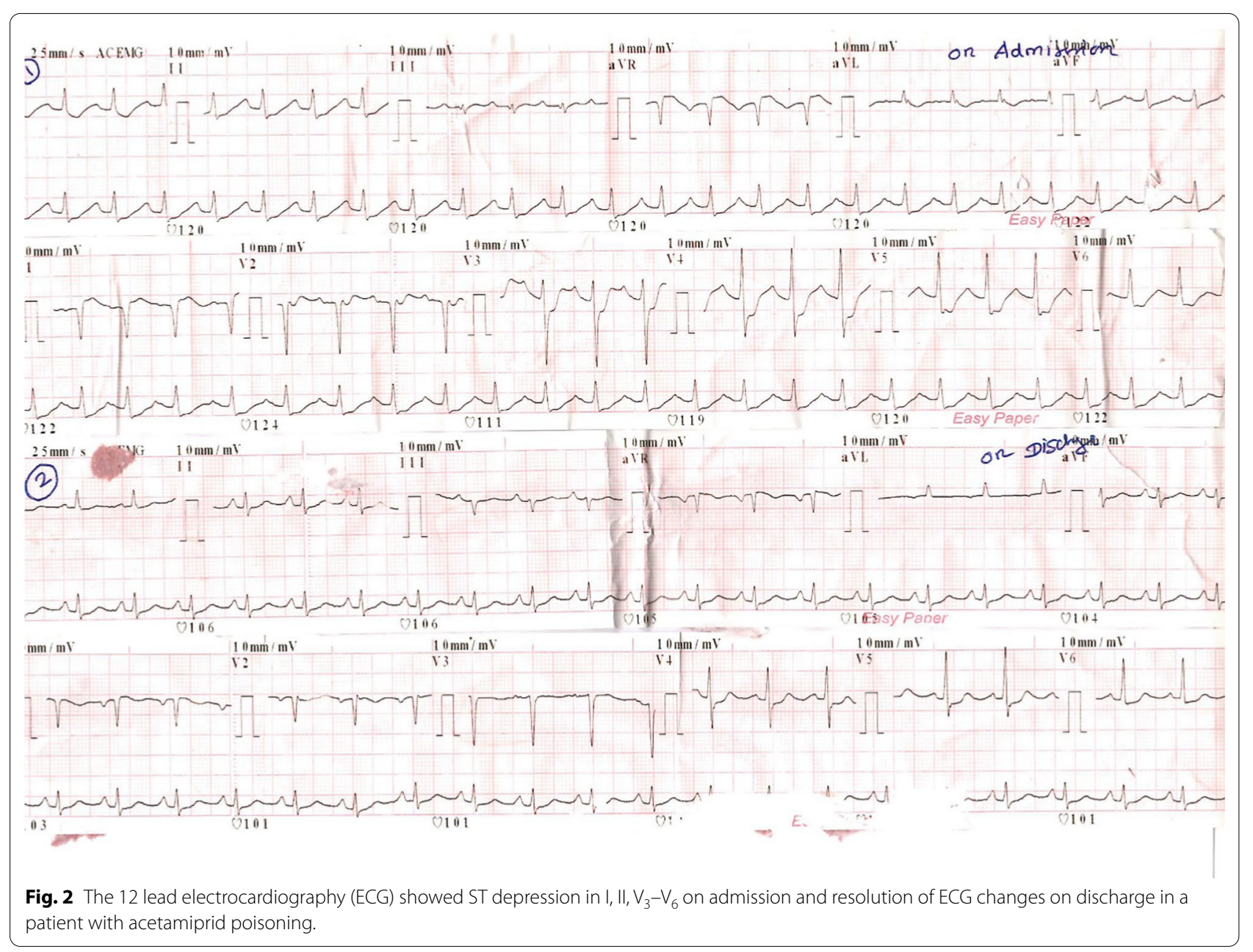

\section{Discussion and conclusions}

Acetamiprid belongs to a new generation of neonicotinoid insecticides that act as selective agonists at nicotinic acetylcholine receptors [5]. Acetamiprid, clothianidin, dinotefuran, imidacloprid, nitenpyram, thiacloprid, and thiamethoxam are common insecticides belonging to this group. Several cases of imidacloprid toxicity were reported in Sri Lanka [6]. However, poisoning with acetamiprid is rare in humans and is not reported in Sri Lanka because neonicotinoids were introduced in market just a few decades ago [7]. Acetamiprid and imidacloprid account for $25 \%$ of global marketing insecticide, but are rarely reported in literature on humans [3, $4,8]$. Although the toxicity for insects is higher than for humans, in humans it causes neuromuscular paralysis and even death [9]. The toxicity can occur through inhalation, ingestion, and dermal contact.
The clinical presentation is similar to that of acute nicotine poisoning, but without corrosive injuries of gastrointestinal tract [5]. The cardiac, respiratory, and neurological symptoms of severe neonicotinoid intoxication are seen among animals [10]. In humans, the toxicity causes nausea, vomiting, respiratory failure, tachycardia, hypotension, muscle weakness, and convulsions [3]. Here, we described a case of acute acetamiprid poisoning in a middle-aged farmer who presented with nausea, vomiting, and altered level of consciousness 1 hour after ingestion.

Acetamiprid reaches high concentrations in liver, kidney, and adrenal gland after extensive absorption from gut in rats [11]. This may be the reason for the increased level of serum bilirubin in the presented case. Electrocardiographic changes noted in the literature include sinus tachycardia, cardiac arrhythmias, and ischemic changes 
Table 1 Biochemical profile of patient with clinical progression of disease

\begin{tabular}{|c|c|c|c|c|c|c|}
\hline \multirow[t]{2}{*}{ Biochemical investigation } & \multirow[b]{2}{*}{ Day 1} & \multirow[b]{2}{*}{ Day 2} & \multirow[b]{2}{*}{ Day 3} & \multicolumn{2}{|l|}{ Date } & \multirow[b]{2}{*}{ Day 6} \\
\hline & & & & Day 4 & Day 5 & \\
\hline \multicolumn{7}{|l|}{ Full blood count } \\
\hline White cell count $\left(4000-11,000 / \mathrm{mm}^{3}\right)$ & 9540 & 10,400 & 10,600 & 11,320 & 10,324 & 10,321 \\
\hline Neutrophils (50-70\%) & 67 & 80 & 87 & 76 & 69 & 75 \\
\hline Lymphocytes (20-40\%) & 32 & 14 & 7 & 23 & 21 & 23 \\
\hline Hemoglobin (12-16 g/dL) & 10.5 & 10.4 & 10.6 & 10.5 & 11.0 & 10.7 \\
\hline $\begin{array}{l}\text { Red cell count } \\
\left(400,000-550,000 \mathrm{~mm}^{3}\right)\end{array}$ & 376,000 & 352,000 & 394,000 & 375,000 & 321,000 & 311,000 \\
\hline Platelets $\left(150,000-450,000 \mathrm{~mm}^{3}\right)$ & 303,000 & 246,000 & 342,000 & 327,000 & 298,000 & 276,000 \\
\hline \multicolumn{7}{|l|}{ Inflammatory markers } \\
\hline ESR (first hour) & - & - & 45 & - & & 35 \\
\hline CRP $(0-1.0 \mathrm{mg} / \mathrm{dL})$ & - & 3.1 & 2.1 & 1.7 & 1.1 & 1.1 \\
\hline \multicolumn{7}{|l|}{ Renal function tests } \\
\hline Blood urea (18-55 mg/dL) & 30 & 23 & 35 & 23 & 35 & 40 \\
\hline Serum creatinine $(0.7-1.5 \mathrm{mg} / \mathrm{dL})$ & 1.17 & 1.51 & 1.83 & 1.64 & 1.1 & 1.1 \\
\hline \multicolumn{7}{|l|}{ Serum electrolytes } \\
\hline Serum sodium (135-145 mmol/L) & 145.2 & 138.1 & 139.1 & 134.9 & 135.6 & 134.8 \\
\hline Serum potassium (3.5-5.0 mmol/L) & 2.39 & 2.4 & 3.1 & 4.2 & 5.2 & 4.5 \\
\hline Serum calcium (8.6-10.2 mg/dL) & - & 8.2 & 8.2 & 8.7 & 8.5 & 8.4 \\
\hline Serum phosphorus (2.6-4.5 mg/dL) & - & 3.5 & 3.1 & 2.7 & 2.8 & 2.3 \\
\hline \multicolumn{7}{|l|}{ Liver profile } \\
\hline Serum aspartate aminotransferase (AST) (0-45 U/L) & 19 & 61 & 188 & 123 & 72 & 47 \\
\hline Serum alanine aminotransferase (ALT) (0-35 U/L) & 15 & 62 & 68 & 34 & 45 & 39 \\
\hline Serum bilirubin $(0-2.0 \mathrm{mg} / \mathrm{dL})$ & 5.6 & 6.14 & 6.13 & 4.1 & 3.1 & 2.1 \\
\hline Serum protein (6.4-8.3 g/dL) & 5.59 & 5.12 & 5.0 & 5.8 & 5.9 & 5.8 \\
\hline \multicolumn{7}{|l|}{ Clotting profile } \\
\hline Prothrombin time/international normalized ratio (PT/INR) $(<1.4)$ & - & 1.4 & - & 1.1 & - & 1.0 \\
\hline Activated partial thromboplastin time (APTT) $(<35 \mathrm{~s})$ & - & 33 & - & 34 & - & 35 \\
\hline High-sensitivity troponin I (< 19 ng/L) & 571 & - & 240.8 & 133.6 & - & 18 \\
\hline
\end{tabular}

AST: Asparate transaminase, ALT: Alanine transaminase, PT/INR: Prothrombin time/International Normalized Ratio, APTT: Activated partial thromboplastin time

[12]. Our patient developed sinus tachycardia and ischemic changes in ECG, as shown in Fig. 2.

The severity of toxicity has no positive correlation with plasma concentration of neonicotinoid concentration. Thus, hemoperfusion has no role in eliminating the toxicity. Supportive therapy and decontamination are recommended among all neonicotinoid-poisoned patients. Gastric lavage was performed, and activated charcoal was given to our patient. He developed severe hypotension, lactic acidosis, hypoxia, and reduced level of consciousness, which required ventilatory support, inotropes, and further supportive therapy. Thirty-six hours later, his symptoms with regard to the effects of acetamiprid were improved, and he was continued on inotropes and ventilator support for 3 days and discharged from hospital on day 6 without any complications.

In the case of acute toxicity, respiratory failure and reduced level of consciousness are the most serious but uncommon complications. The clinical consequences of acetamiprid poisoning are not very well described. Therefore, such information is valuable for clinicians, regulatory authorities, and the public at large. Furthermore, clinical outcomes depend on early recognition and aggressive supportive management since there is no antidote available. 

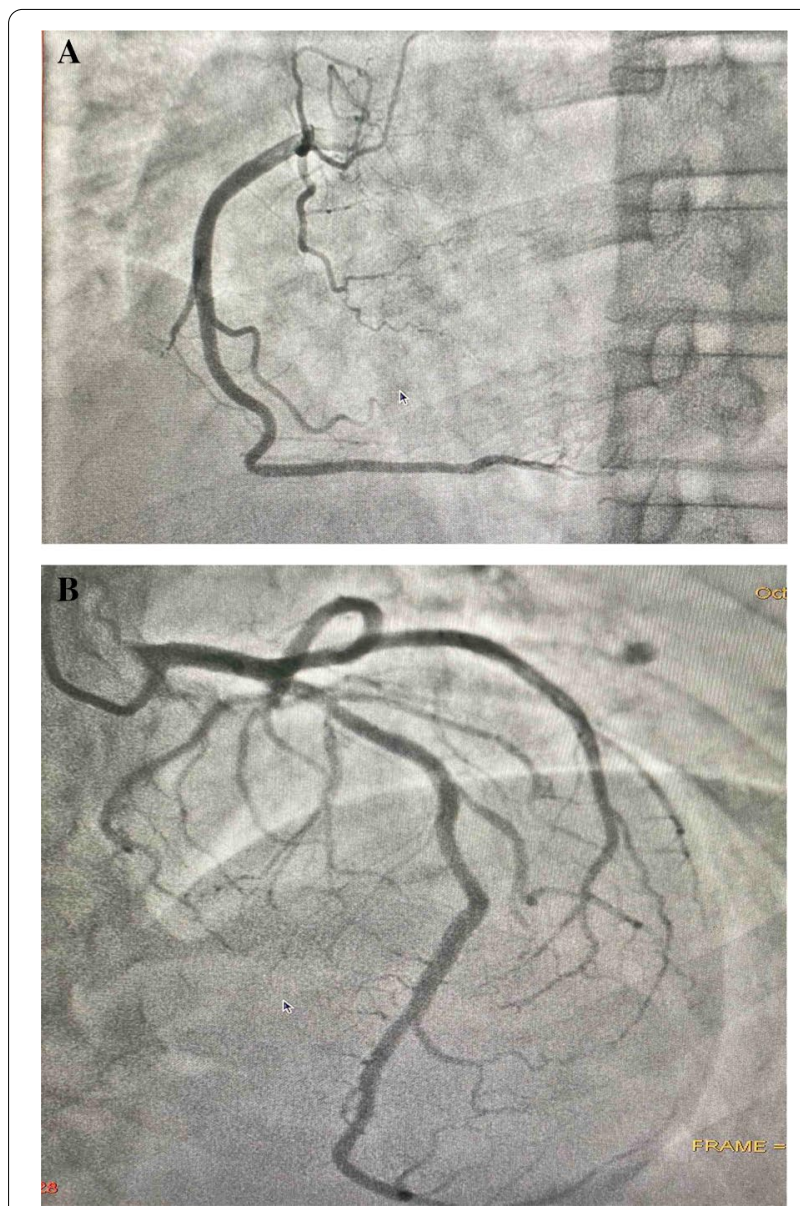

Fig. 3 A, B Coronary angiography showing normal right (A) and left coronary arteries $(\mathbf{B})$ in a patient with acetamiprid poisoning

\section{Abbreviations}

GCS: Glasgow Coma Scale; ECG: Electrocardiography; 2D Echo: Two-dimensional echocardiography; ESR: Erythrocyte sedimentation rate; CRP: C-reactive protein.

\section{Acknowledgements}

Not applicable.

\section{Authors' contributions}

$\mathrm{SP}, \mathrm{RS}, \mathrm{CA}, \mathrm{MG}, \mathrm{MG}$, and $\mathrm{AG}$ examined, assessed, and were involved in the management of the patient. All authors collected and analyzed data. All authors read and approved the final manuscript.

\section{Funding}

Not applicable.

\section{Availability of data and materials}

All the data generated or analyzed during this study are included in this article and its supplementary information files.

\section{Declarations}

\section{Ethical approval and consent to participate}

Our institution does not require ethical approval for reporting individual cases or case series.

\section{Consent for publication}

Written informed consent was obtained from the patient for publication of this case report and any accompanying images. A copy of the written consent is available for review by the Editor-in-Chief of this journal.

\section{Competing interests}

The authors declare that they have no competing interests.

\section{Author details}

${ }^{1}$ District General Hospital, Kilinochchi, Sri Lanka. ${ }^{2}$ Teaching Hospital, Jaffna, Sri Lanka. ${ }^{3}$ Faculty of Medicine, University of Colombo and National Hospital of Colombo, Colombo, Sri Lanka. ${ }^{4}$ llavalai North, Ilavalai, Jaffna, Sri Lanka.

Received: 11 December 2020 Accepted: 20 May 2021

Published online: 30 July 2021

\section{References}

1. Tomizawa M, Casida JE. Selective toxicity of neonicotinoids attributable to specificity of insect and mammalian nicotinic receptors. Annu Rev Entomol. 2003;48:339-64.

2. Kushwaha N, Mohan A, Bhikane AU. Accidental acetamiprid poisoning in a buffalo. IJVR. 2018:19(4):318-20.

3. Imamura T, Yanagawa Y, Nishikawa K, Matsumoto N, Sakamoto T. Two cases of acute poisoning with acetamiprid in humans. Clin Toxicol. 2010;48(8):851-3.

4. Totani M, Kaneko T, Hayashida H, Kaneda K, Tsuruta R, Kasaoka S, Maekawa T. Acute poisoning with neonicotinoid insecticide acetamiprid. Jpn J Toxicol. 2008;21:387-90.

5. Chao SL, Casida JE. Interaction of imidacloprid metabolites and analogs with the nicotinic acetylcholine receptor of mouse brain in relation to toxicity. Pestic Biochem Physiol. 1997;58:77-8.

6. Mohamed F, Gawarammana I, Robertson TA, Roberts MS, Palangasinghe $C$, et al. Acute human self-poisoning with imidacloprid compound: a neonicotinoid insecticide. PLoS ONE. 2009;4(4):e5127.

7. Chiyozo T. The history of insecticides and the transition of their production. Jpn J Toxicol. 2008;21:123-31.

8. Lin P-C, Lin H-J, Liao Y-Y, Guo H-R, Chen K-T. Acute poisoning with neonicotinoid insecticides: a case report and literature review. Basic Clin Pharmacol Toxicol. 2013;112:282-6.

9. Nauen R, Denholm I. Resistance of insect pests to neonicotinoid insecticides: current status and future prospects. Arch Insect Biochem Physiol. 2005;58:200-15.

10. Lin PC, Lin HJ, Liao YY, Guo HR, Chen KT. Acute poisoning with neonicotinoid insecticides: a case report and literature review. Basic Clin Pharmacol Toxicol. 2013;2013(112):282-6.

11. JMPR (Joint FAO/WHO Meeting on Pesticide Residues). Pesticide residues in food - 2000. Report of the Joint Meeting of the FAO Panel of Experts on Pesticide Residues in Food and the Environment and the WHO Core Assessment Group. FAO Plant Production and Protection Paper; 2001. p. 167.

12. Taira K, Aoyama Y. Electrocardiographic manifestations and seasonal changes in patients with cardiac symptoms and headache in the area where neonicotinoid and organophosphate insecticides were spread in 2005. Jpn J Clin Ecol. 2006;15:114-23.

\section{Publisher's Note}

Springer Nature remains neutral with regard to jurisdictional claims in published maps and institutional affiliations. 